\title{
The "Mosaic" Approach, a Working Alternative in the Public Preschool Institutions in Kosovo
}

\author{
Rozafa Ferizi Shala PhDc. \\ Teaching assistant at the Faculty of Education, University of Prishtina, Kosova, PhD candidate, Faculty of Social Science \\ University of Tirana, Albania; Email: rozafa.ferizi-shala@uni-pr.edu
}

\section{Doi:10.5901/mjss.2015.v6n5s1p30}

\section{Abstract}

\begin{abstract}
The preschool education in Kosovo based on International Standard Classification of Education (UNESKO) presents its level 0. It is organised in Public, Private Preschool Institutions, Community based centres and for the children of age 5-6 preparatory classes are offered within primary schools. The "Mosaic" programme is one of the programs that started to be implemented in several preschool institutions, initiated by Save the Children organisation. The way the program is implemented, the effects of its implementation and continuity of program extension after the termination of the project are some of the focuses of this research. The research is qualitative and one of the public institutions where the Mosaic model is implemented has been selected randomly. Data collection is organised in three levels, including: semi structured interview with the Preschool Institution administrator, semi structured interview with the educators implementing the program and direct observation of the work in the institution. Data extracted from the research state the unsustainability of the program after the termination of the project and the difficulties of its full implementation. Constituting elements of this program are evident in the day to day practice in the Institution, such as: usage of observation forms and some of the programme activities. The conclusions achieved and recommendations made based on the study performed shall serve as a good opportunity to increase the lifespan of the programmes, based on their efficiency and usability even after the projects are over.
\end{abstract}

Keywords: Public Preschool Institution, the "Mosaic" Programme, viability, educators, children.

\section{Introduction}

Kosovo is a new country, it has many challenges ahead, a challenge not yet overpassed is the provision of overall services for access to quality education for children in the early childhood. We may argue that the poor tradition in the field of offering services to the children in the early childhood mainly was influenced by socio-economic and political circumstances that accompanied our country in the end of last millennium. Since after war (1999), the education system in general, including preschool education in the country, went through many transitional processes. The role of the humanitarian organisations, including governmental and non-governmental organisations, in this process is undeniable. Provision of on-going assistance and support in the development of education sector influenced in many fields, such as: legal field, creation of new spaces, improvement of infrastructure, educator's training, provision of different preschool education programmes, etc.

At the moment in Kosovo, the preschool education continues to be voluntary based and not mandatory by state, and that influences directly on the way the importance of enrolling or not enrolling children in preschool institutions is perceived. The level of inclusiveness of children in the early childhood in the institutionalised education continues to be quite low compared to the countries in the region and the European countries. However, despite difficulties in creating the conditions for all-inclusiveness in preschool education, it is very important to follow up the quality of work offered to the children that already are part of the institutionalised education. To prevent prejudices and ethnical divisions among children in Kosovo, created based on socio political circumstances created in the country, the Save the Children organisation started the implementation of Mosaic approach in Kosovo. The model was initially applied in Macedonia and it was evaluated as a successful working practice.

\subsection{Literature review}

There are many preschool education programs internationally known, used in different countries in the world. Each programme has its own specifics that make it an alternative programme for work with children. The combination of the bilingual approach and activities, whose ground is child raising on basis of cultural, ethnic, religious, gender, etc. diversity, 
helps to prevent emerging of prejudices and different stereotypes from the children at an adult age. The Mosaic model and its correct implementation in practice by educators and the support of the parents will help in creating an environment where everyone shall feel equal in the society where he/she lives irrespective differences we might have.

In a study done by Au, Knightly, Jun, \& Oh (2002), which has to do with learnig a language by hearing it during early chldhood and the importance this way of learning has in an older age. Researchers found good relations in beetween speaking accent developent in Spanish at children who faced with the usage of this language during early childhood. Results of this study are important in regard to usage of mother tongue from those living in other countries and facing with a second language since early childhood. Based on Au, Knightly, Jun, \& Oh (2002) waiting until adulthood to learn a language almost guarantees bad accent, having overheard the target language during childhood seems to lessen this predicament substantially. So, the best time to teach children a second language is probably during early or middle childhood, but the best time to learn two languages without teacher's help, by exposing to them (and also learn the natural pronunciation on the two languages) is the early childhood (Woolfolk, 2010, p. 56). In the Mosaic, the groups of children are combined according to the language the child uses in communication, i.e. their native language are two different languages, for example: Albanian-Bosnian, Albanian-Turkish and Albanian-Serbian.

According to Vygotsky (1978) children learn speech from adults, or that, through asking questions and giving answer, children acquires a variety of information; or that through imitating adults and through being instructed about how to act, children develop an entire repository of skills? Learning and development are interrelated from the child's very first day of life.

The programme is designed in parallel use of two languages and development of natural and fluent communication in both languages. Two educators work with a mix group of children from the two groups using different languages for communication, and they also belong to two groups that use different language for day to day communication (not necessarily ethnic based separation of groups should take place). The special thing for the programme is that the educators communicate fluently in both languages and so they create equal opportunities in communication and interaction with all the children in the two languages the model is applied. The group working with the Mosaic model uses the same working program as the other groups, bur the approach to activities is different in a positive view. "The pedagogical approach of the Mosaic promotes modern ways of teaching with children, working on the fields of different interests, including IT application and different appropriate materials focused on problem solution. The Mosaic involves children to be active participants in the teaching and emphasizes flexibility and creativity. Hence, the pedagogical approach of the Mosaic has children and their participation in the centre and enables the development of children creativity in different fields of interest. The educators of Mosaic are qualified in implementing the newest approaches of teaching in computer equipped environments, furniture suitable and safe for children and educational resources of high quality" (Hoti, Kacapor, \& Gowing, 2008, p. 13). The Mosaic model, besides the bilingual component, includes the multiculturalism as a social value that should be cultivated from an early age.

According to E. Gowing (2008) by understanding how the children learn the language, the educators and parents of the Mosaic can support their children effectively in developing their language skills on the two languages used in the Mosaic class (Hoti, Kacapor, \& Gowing, 2008). It is more than known that children in early childhood are not expected to master the whole language that they listen less but staying in a kindergarten where both languages are spoken in parallel is very fruitful for children of both ethnic groups. In the study by Oh, Jun, Knightly, \& Au (2002) the main focus is to see long-term benefits of early language experience. They compared the perception and production of Korean speech sounds by childhood speakers who had spoken Korean regularly for few years during childhood to that of two other groups of adult learners. The participants in this research were enrolled in first-year, college level Korean language classes. The results revealed measurable long-term benefits of childhood speaking experience, underscoring the importance of early language experience, even if such experience diminishes dramatically beyond childhood. Except for interaction in two languages, the way the interaction develops and the time available for the child to work independently and reflectively is quite important. According to Vygotsky (1978) internal speech and reflective thought arise from the interaction between the child and person in his environment, those interaction provide the source of development of child's voluntary behaviour. In kindergartens where the Mosaic model is used, learning is developed through games, finding out new things and the work in small groups. That reflects the modern methods of cooperation and non-competitive models of solving problems. Being aware that children from age $3-5$ years old possess high perception ability, the above mentioned activities shall have a great impact on the growth and development of children (Hoti, Kacapor, \& Gowing, 2008). 
The Mosaic programme is a multicultural and bilingual programme, offered within public preschool institutions for children of age 3-5. The programme uses bilingual pedagogic approach oriented on children of different ethnic and lingual affiliations (Hoti, Kacapor, \& Gowing, 2008), the approach ensures a better communication between different cultures, languages, traditions and ensures intercultural communication. According to Vilma Venkovska- Milçev: Search for Common Ground (SFCG) Organisation in its programmes implemented a special approach, by recognising differences and relying on similarities, SFCG offers opportunities for people of different ethnic affiliations to work together on their concerns and find their common elements. In this regard (SFCG) on 1997 created the Mosaic project, where children in their early age, when they have no prejudices and stereotypes for their peers are socialised in neutral environment and all children are evaluated equally (Hoti, Kacapor, \& Gowing, 2008). Based on the successful practice of this program in Macedonia for the time it was implemented by SFCG, Save the Children in Kosovo in cooperation with the Ministry of Education, Science and Technology started the program in a number of preschool institutions all over the territory of Kosovo. According to A. Kajtazi, the successful accomplishment and extension of the "Mosaic" project, is taking place in five preschool institutions: Prishtina (Albanian-Turkish group), Prizren (two groups Albanian-Turkish and AlbanianBosnian), Obiliq (Albanian-Serbian), Kamenica (Albanian- Serbian) and Peja (Albanian-Bosnian)(Kajtazi, 2008).

\section{Methodology}

This study is a qualitative study, and the main focus has to do with the way the Mosaic model was implemented in practice, the effects of the programme, its applicability in practice and maintenance of programme continuity even after the project is over. The Mosaic model was implemented by Save the Children organisation and supported by the Ministry of Education, Science and Technology. But, where is the programme now? How is it progressing? Has the preschool institution achieved to keep alive the main features of this programme even with no support? These are research questions on which the whole research work is built.

Since in our country, this working model is used in 5 preschool institutions, in cities such as: Prishtina (AlbanianTurkish group), Prizren (two groups Albanian-Turkish and Albanian-Bosnian), Obiliq (Albanian-Serbian), Kamenica (Albanian- Serbian) and Peja (Albanian-Bosnian). From these five cities, randomly only one of them was selected. The institution selected randomly was the Preschool Institution "Pëllumbat e Paqës" in Peja. The reason why only an institution was selected has to do with the achievement of unique and characteristic data on the way the programme is implemented. Data from the study will be special and not generalised since there is a number of factors that favour or disfavour the way the working model is applied in the preschool institution.

Being aware of the characteristics and differences in perception and diversity acceptance, especially the ethnic and lingual one, the model is meant to be analysed only in preschool institutions, which, as mentioned, was chosen randomly.

Data collection is organised based in three different resources, (1) the director of the institution, (2) educators implementing this programme and (3) direct observation during the activities with the children. For the information to be full and the data precise, two measuring instruments have been prepared: a semi-structured interview with the institution director and a semi-structured interview with the educators implementing the programme. While the observation in the preschool institution is done by the researcher herself in a typical working day.

\section{Results from Interviews and Observation}

The results shall be analysed in a special way for every part of the study, to have a much more comprehensive argumentation. While reviewing the results only the data related to the focus of this study shall be analysed.

\subsection{Results from the interview with the director of the Preschool Institution}

The interview took place in the Institution premises and the conditions for the interview were optimal. In this institution, the bilingual Albanian and Bosnian Mosaic model is applied. The director of the Institution implied that the number of children from Bosnian community is small and there is no possibility to organise a Mosaic model as required by the working program. But elements of the Mosaic program, such as observation portfolios and different cultural activities have been maintained and are still used by the educators that were trained for the Mosaic.

The number of children from Bosnian community is 1 child under 3 years old, 1 child in the $4-5$ group age and a child in the 5-6 group age.

With the group ages of children above 3 years old there is an extra educator working with them, whose 
communication language is Bosnian language, but the number of activities developed in the two languages is highly limited.

According to the director of the Institution, there is no mechanism that would stimulate educators to continue the application of a working model even after the termination of the project. Often, with the finalisation of the project or the certification on a specific program, the reasonability of the educators to apply the programme in practice is over too. Educator's self-motivation for work continues to be a very important element making them responsible for the job. On the other side, the Institution, according to the director, attempts continually to maintain the motivation of educators at work.

\subsection{Results from the interview with the educators}

The educators of the Mosaic model, prior to the work with this model, followed a six months training and were part of the study visit in Macedonia, to acquire as much as possible the constituent components of the program before they begin the work with the children. The educators told us about the first phases of the project, the barriers by the parents in regard to the work in two languages and their success in overcoming them through on-going work with them. The educators affirm that it has been necessary to work continuously with the parents, so that they approve and help the process of bilingual learning and multiculturalism as a social value that should be cultivated. Overcoming these barriers, the educators achieved to arrange family visits as well at the Albanian and Bosnian families with the whole group, they achieved to get familiar with the habits and traditions of the two communities without distinction, creating a natural environment for learning the two languages and their two cultures.

But, with the termination of the project, this working model started to move away from its goal, reducing activities and the hard work on developing bilingualism and multiculturalism. The educators believe the problem is also the small number of children, whose communication language is Bosnian language, hence they qualify this as one of the factors that made this working model be present less and less in the Institution.

Currently one of the educators in her group has a child whose primary language is Bosnian. The educator tells how she communicates simple words that have to do with the active lexis of the child in Bosnian and also in English, so that other parents do not create prejudices. The game, integration and children activity is joint but the instructions most of the time are given only in one language, while during the joint meetings or different discussions the educator communicates with the child in Bosnian as well but in this case it doesn't have to do with the Mosaic model, but with the child's right to learn in native language.

\subsection{Results from the observation of day to day activities}

The observation took place in regular working conditions and started with the start of daily activities. Some of the qualities worth to be mentioned are: the children integration in common activities and the positive climate among children despite the fact that in their group there was a child whose communication language was not Albanian language. During activity and game the child functioned normally. The class was suitable for developing activities but the lack of didactic materials for playing and independent work of children was largely noticeable.

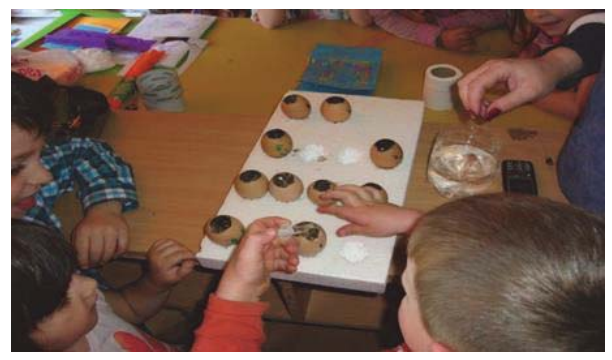

Figure 1. The children during the closing activity (Preschool Institution "Pëllumbat e Paqës" Pejë)

The figure 1. presents the children watering the plants they had planted two days ago. During the process a very fruitful discussion emerged, on the way a plant grows and conditions in which it can grow. Any child would develop himself the same process. 
There was a very good interconnection of activities in the classroom and those outside, since the institution itself provided for such a possibility, because each of the working environments had access to outside spaces in the institution's yard.

Every child had its own working file and a personal box where all the materials worked and the drawings were collected. During the observation, it was not noticed that the educators use these materials for the evaluation of child's progress, although informally they did so but it was not documented in written. The educator uses observation sheets of the Mosaic model to evaluate the children progress.

\section{Discussion}

The advantages of bilingual programmes are extraordinarily great and with long term benefits, that is proved by several researches performed in the world. From the study done with the children speaking English and Spanish by Au, Knightly, Jun, \& Oh (2002) it comes that hearing a language, althought not full time during the experience the child has in his early childhood, has great benefits in later stages of his life. In addittion, the study performed by Oh, Jun, Knightly, \& Au (2002) with Corean students proves a good correlation between lingual experiences in early childhood and easement in spelling in adult age. Althought, Mosaic started to be implemented from 2008, no evaluation was done in regard to benefits in lingual aspect for the children who have been part of this programme. While in regard to creation of a better communication climate and cooperation between ethnicities, the results were evident and will be mention in the conclusion.

\section{Conclusion}

The Mosaic may be considered successful and fruitful only for the time it was under the supervision of Save the Children organisation. The footprints of the programme are present through activities and games but we cannot say the philosophy of the Mosaic model is present within this Institution.

Maintaining the continuity of a programme after the project is over is a challenge for our system of education, since for every project that includes educators, everything always has to start from the beginning. The lack of an on-going monitoring, the lack of professional consultancy and lack of special inspectors in the field of preschool education are three problems, whose impact is extremely great in maintaining the good practices of the work with children.

The good practice with children requires for continuity of activities and working ways, whereby the ruining of the previous experiences and establishment of a new working model is accompanied with numerous difficulties. The maintenance of the continuity of the positive working practices despite the projects in which the institution is involved and maintenance of educator's self-motivation for work are two of the main cornerstones from where we can build a sustainable program of work with the children. This programme should comply with the local requests and context, its base is the creation of sustainable values in children and their supply with knowledge and skills that correspond to the $21^{\text {st }}$ century requests and are comparable internationally, irrespective the name of the programme the educator uses with children.

\section{Study Limitations}

The data are gathered and argued in a quality point of view. Based on the way this working model is developed in our country, the data from this study cannot be generalised, but may be used as a model from other countries with an approximate context as Kosovo.

\section{References}

Au, T. K., Knightly, L. M., Jun, S.-A., \& Oh, J. S. (2002). Overhearing a language during childhood. Psychological Science, 13, $238-243$.

Hoti, D., Kacapor, S., \& Gowing, E. (2008). Mosaic: Access to preschool education, multicultural and bilingual children:. Prishtinë: Save the Children.

Kajtazi, A. (2008). Division for preschool education . Retrieved January 19, 2014, from Ministry of Education, Science and Technology: http://www.masht-gov.net/advCms/?id=1549\&lng=Alb

Oh, J. S., Jun, S. A., Knightly, L. M., \& Au, T. K. (2002, August). Holding on the childhood language memory. Cognition, 86(3), B53 - B6 4.

Vygotsky, L. (1978). Interaction between learning and development. In L. Vygotsky, Mind and society (pp. 79-91). Cambridge, MA: Harvard University Press.

Woolfolk, A. (2010). Educational psychology (Eleventh edition ed.). Pearson. 